\title{
Note added in proof to: Molecular characterization of the pentacyclic triterpenoid biosynthetic pathway in Catharanthus roseus
}

\author{
Lili Huang $\cdot$ Jia Li $\cdot$ Hechun Ye $\cdot$ Changfu Li $\cdot$ \\ Hong Wang $\cdot$ Benye Liu $\cdot$ Yansheng Zhang
}

(C) Springer-Verlag 2012

Functional characterization of amyrin synthase involved in ursolic acid biosynthesis in Catharanthus roseus leaf epidermis by Yu et al. (2012) characterizes the same amyrin synthase gene as described in this manuscript.

\section{Reference}

Yu F, Thamm AMK, Reed D, Villa-Ruano N, Quesada AL, Gloria EL, Covello P, De Luca V (2012) Functional characterization of amyrin synthase involved in ursolic acid biosynthesis in Catharanthus roseus leaf epidermis. Phytochemistry http://dx.doi.org/ 10.1016/j.phytochem.2012.05.002 [Epub ahead of print]

The online version of the original article can be found under doi:10.1007/s00425-012-1712-0.

L. Huang $\cdot$ J. Li $\cdot$ C. Li $\cdot$ Y. Zhang $(\square)$

CAS Key Laboratory of Plant Germplasm Enhancement and Specialty Agriculture, Wuhan Botanical Garden, The Chinese Academy of Science, Wuhan 430074, China

e-mail: zhangys@wbgcas.cn

L. Huang $\cdot$ H. Ye $\cdot$ B. Liu

Key Laboratory of Plant Molecular Physiology,

Institute of Botany, The Chinese Academy of Science,

Beijing 100093, China

e-mail: benyel@ibcas.ac.cn

L. Huang $\cdot$ H. Wang

Graduate University of the Chinese Academy of Science,

Beijing 100049, China 